DOI: 10.17707/AgricultForest.62.2.21

\author{
Elizabeta DIMITRIESKA-STOJKOVIĆ, \\ Aleksandra ANGJELESKA, Goran STOJKOVIĆ, Risto UZUNOV, \\ Biljana STOJANOVSKA-DIMZOSKA, Zehra HAJRULAI-MUSLIU ${ }^{I}$

\section{MONITORING OF MULTI-CLASS PESTICIDES IN HONEY SAMPLES FROM MACEDONIA BY ULTRA HIGH PERFORMANCE LIQUID CHROMATOGRAPHY - TANDEM QUADRUPOLE MASS SPECTROMETRY}

\begin{abstract}
The possible presence of pesticide residues in honey has impelled the need for setting up monitoring programs to determine the proper assessment of human exposure to pesticides. This paper describes an effective multi-class method using a modified QuEChERS sample preparation for detection and quantification of 18 pesticides with Ultra-high-performance liquid chromatography (UHPLC) tandem quadrupole mass spectrometry. The method was validated according to the requirements laid down in DG SANCO 12571/2013 document. Levels of detection and quantification were lower than the established MRLs, the obtained precision was better than $20 \%$, and the recovery values were between 74.4 and $104.1 \%$. Fifty honey samples within the national monitoring program were collected from August to November, 2014 and tested for presence of carbaryl, carbofuran, fenvalerate, cypermethrin, deltamethrin, permethrin, bifenthrin, amitraz, coumaphos, bromopropylate, dichlorvos, diazinone, malathion, parathion, dimethoate, omethoate, methomyl and thiametoxam. Trace levels of methomyl, diazinone, bromopropylate and fenvalerate were detected somewhat above the reporting level for these pesticides $(10 \mu \mathrm{g} / \mathrm{kg})$. This contamination indicates on existing of possible moderate cross-contamination during pollen and nectar collection by bees, and residues of substances used in beekeeping. Although traces of pesticides were found in 16 of the samples tested (32\%), the levels found did not pose increased toxicological risk for the population.

Keywords: pesticides, honey, multi class method, liquid chromatography, tandem quadrupole, QuEChERS.

\footnotetext{
${ }^{1}$ Elizabeta DIMITRIESKA-STOJKOVIĆ (corresponding author:edimitrieska@ fvm.ukim.edu.mk ), Aleksandra ANGJELESKA, Risto UZUNOV, Biljana STOJANOVSKA-DIMZOSKA, Zehra HAJRULAI-MUSLIU,Ss Cyril and Methodius University, Faculty for veterinary medicine, Institute for food Lazar Pop-Trajkov 5, Skopje MACEDONIA, Aleksandra ANGJELESKA, Ss Cyril and Methodius University, Faculty of natural sciences and mathematics, Institute of chemistry Arhimedova 5, Skopje MACEDONIA.

Note: The authors declare that they have no conflicts of interest. Authorship Form signed online.
} 


\section{INTRODUCTION}

Honey is a valuable commodity that can be used as a final product or food ingredient. It is a highly-energetic natural carbohydrate product containing significant number of compounds with high benefit for the humans (Eissa et al. 2014). The quality of honey is mainly determined by its sensorial, physicochemical and microbiological characteristics. The honey quality criteria are well defined by the EC Directive 2001/110 (EC, 2001). Agricultural contamination of food with pesticides is a challenging problem that could not be neglected. In recent years, analysis of pesticide residues in food becomes a substantial requirement for consumers, producers and food safety authorities (Eissa et al. 2014). Pesticide residues might cause genetic mutations and cellular degradation, thus presenting a potential risk for the human health, mainly due to their cumulative properties (Blasco et al. 2003).

The analysis of pesticides residues in honey is significant analytical challenge, due to the complex and variable honey composition dependable on the type of plant where bees collect nectar (Tomasini et al. 2012). It is considered that there are two forms of contamination of honey: during pollen and nectar collection of bees, indirect contamination and through treatment of hives, in which pesticides can migrate in honey, i.e. direct contamination (Orso et al. 2014). The evidence for the presence of pesticide residues in honey (Blasco et al. 2003, Orso et al. 2014) has impelled the need for setting up monitoring programs for obtaining a proper assessment of human exposure to pesticides through honey consumption (Wallner, 1999). Different national regulations have established maximum permitted concentrations of pesticides (MRLs) in honey, but the lack of harmonized regulative cause problems in international trade (Blasco et al. 2003).

Many publications have reported various extraction methods for determination of pesticide residues in honey, employing solid phase-extraction (SPE), matrix solid-phase dispersion (MSPD), supercritical fluid extraction (SFE) and accelerated solvent extraction (ASE) (Amendola et al. 2011). The pesticide determination is usually performed by GC or LC coupled with various detectors. Only few of these methods allow multi-class detection of pesticide residues, as well as their quantification at very low concentration levels. In the recent years MSPD sample preparation has been identified as powerful tool for multi-residual analysis of pesticides in honey samples due to its compatibility both with GC and LC chromatographic systems and mass spectrometric detection systems (Tomasini et al. 2012; Orso et al. 2014, Rodríguez-López et al. 2014; Fidente et al. 2005; Tanner and Czerwenka, 2011).

The lack of information about pesticide residues in honey samples from Macedonia implies the necessity to determinate the pollution of this bee product. 
Accordingly, the aim of this study was to identify the current honey contamination with 18 pesticides applying validated multi-class ultra highperformance liquid chromatography (UHPLC) - tandem mass spectrometry method. On basis of pesticides found in a representative number of 50 honey samples, we could conclude whether the honey samples were exposed to direct or indirect contamination, as well as their safety from the toxicological point of view.

\section{MATERIAL AND METHODS}

Chemicals and materials

As an analytical standards carbaryl, carbofuran, fenvalerate, cypermethrin, deltamethrin, permethrin, bifenthrin, amitraz, coumaphos, bromopropylate, dichlorvos, diazinone, malathion, parathion, dimethoate, omethoate, methomyl and thiametoxam were purchased from Fluka (Pestanal quality). Acetonitrile was with HPLC grade, while methanol and water were with LC/MS grade, all supplied from Carlo Erba. Formic acid (Suprapur grade) and ammonium formate were products of Sigma-Aldrich. The sorbents used for MSPD were magnesium sulfate anhydrous (Merck), sodium chloride (Carlo Erba), primary-secondary amine - PSA and C-18 (Supelco).

\section{Sample collection}

A total of 50 multifloral honey samples were collected at individual beekeepers from different geographical locations in Macedonia in the period August-November, 2014. Upon collection, all honey samples were placed into clean glass jars, labeled and placed on $+4 \mathrm{oC}$, transferred to the laboratory and kept at $4 \mathrm{oC}$ until analysis. The sample size needed for obtaining the required sample homogeneity was at least $500 \mathrm{~g}$.

\section{Sample preparation: modified QuEChERS procedure}

The extraction method used was based on the original QuEChERS method developed by Anastassiades et al. (2003). Briefly, for the extraction, $5.0 \mathrm{~g}$ of honey was weighed in a $50 \mathrm{~mL}$ polypropylene centrifuge tube and $10 \mathrm{~mL}$ of water was added. The mixture was vortexed for 1 min. Afterwards $10 \mathrm{~mL}$ acetonitrile was added and the sample was homogenized. After adding $4 \mathrm{~g}$ magnesium sulfate and $1 \mathrm{~g}$ sodium chloride, the sample was vortexed again and centrifuged at $8000 \mathrm{rpm}$ for $10 \mathrm{~min}$. Six $\mathrm{mL}$ of the upper layer was placed into 15 $\mathrm{mL}$ polypropylene tube containing $900 \mathrm{mg}$ magnesium sulfate, $150 \mathrm{mg}$ PSA and $150 \mathrm{mg} \mathrm{C}-18$ sorbent. After $1 \mathrm{~min}$ homogenization the tube was centrifuged at $3000 \mathrm{rpm}$ for $5 \mathrm{~min}$. Four $\mathrm{mL}$ of the solution were evaporated to dryness, redissolved in $2 \mathrm{~mL}$ mobile phase, filtered through $0.45 \mu \mathrm{m}$ filter and placed into autosampler vial and further analyzed with UHPLC-TQD system. 


\section{Instrument and experimental conditions}

UHPLC with mass spectrometric detection was performed on Acquity TQD Waters system (Waters, Milford, MA, USA), utilizing Ascentis ${ }^{\circledR}$ Express of $2.7 \mu \mathrm{m}$ particle size, $50 \mathrm{~mm}$ length and $2.1 \mathrm{~mm}$. i.d. (Supelco, Bellefonte, PA, USA). Source temperature was $150 \mathrm{oC}$, desolvation temperature $450 \mathrm{oC}$. Detection by MS/MS was performed using electrospray ionization (ESI) operating in positive mode. For each compound the optimum collision energies with aim of getting two multiple reaction monitoring (MRM) transitions with the best signal intensity were selected.

The mobile phase components for the UHPLC system were methanol (A) and water (B), both modified with $0.1 \%$ formic acid and $5 \mathrm{mM}$ ammonium formate, applying suitable gradient program. The flow rate was $0.6 \mathrm{~mL} / \mathrm{min}$ and the total run time $23.10 \mathrm{~min}$.

\section{Method validation}

The optimized UHPLC-MS/MS method employing modified QuEChERS sample preparation was validated regarding the requirements laid down in SANCO Guidance document on analytical quality control and validation procedures for pesticide residue analysis in food and feed (SANCO, 2013). Accordingly, the method validation includes the following parameters: limits of detection and quantification (LODs and LOQs), linearity, precision and recovery. The range of determination was $5-250 \mathrm{ng} / \mathrm{mL}$, the precision and accuracy was estimated at reporting level $10 \mu \mathrm{g} / \mathrm{kg}$ and five times reporting level i.e. $50 \mu \mathrm{g} / \mathrm{kg}$.

\section{RESULTS AND DISCUSSION Optimization of the LC-ESI-MS-MS parameters}

The chromatograms were recorded in MRM mode with ESI interface in positive ionization mode. The MRM analysis introduces high method specificity based on the detection of both parent ion and one of its known fragments (Sampaio et al. 2012). For each compound, the in-house optimized collision energies were selected with the aim of getting two characteristic MRM transitions with the best intensity (Table 1).

The main advantage of the method was the application of MS/MS since it provides high confidence level for identification of the target pesticides. The monitoring of the second fragmentation products allows more efficient discrimination of the interfering matrix, than the products of the primary fragmentation (Sampaio et al. 2012). The first MRM transitions exhibited higher signals and accordingly higher sensitivity, thus, they were used for quantification of the compounds examined. The second MRM transitions are so-called target ions and are mandatory for confirmatory purposes. 
Table 1. MRM conditions for the simultaneous determination of pesticides with electrospray ionization in positive mode (dwell time $0.025 \mathrm{~s}$ )

\begin{tabular}{|c|c|c|c|c|c|}
\hline Pesticide & $\begin{array}{c}\text { Parent } \\
\text { ion } /(\mathrm{m} / \mathrm{z})\end{array}$ & $\begin{array}{c}\text { Product } \\
\text { ion } /(\mathrm{m} / \mathrm{z})\end{array}$ & $\mathrm{CV}^{\mathrm{a}} /(\mathrm{V})$ & $\mathrm{CE}^{\mathrm{b}} /(\mathrm{eV})$ & $\mathrm{RT}^{\mathrm{c}} /(\min )$ \\
\hline Carbaryl & 202.0 & $\begin{array}{l}202>127.1 \\
202>145.1\end{array}$ & $\begin{array}{l}22 \\
22\end{array}$ & $\begin{array}{l}15 \\
10\end{array}$ & 5.87 \\
\hline Carbofuran & 222.1 & $\begin{array}{l}222.1>123.1 \\
222.1>165.1\end{array}$ & $\begin{array}{l}80 \\
80\end{array}$ & $\begin{array}{c}20 \\
5\end{array}$ & 5.47 \\
\hline Fenvalerate & 420.4 & $\begin{array}{l}420.4>145.1 \\
420.4>219.2\end{array}$ & $\begin{array}{l}12 \\
12\end{array}$ & $\begin{array}{l}32 \\
10\end{array}$ & 5.72 \\
\hline Cypermethrin & 165.1 & $\begin{array}{l}165.1>55.0 \\
165.1>72.0\end{array}$ & $\begin{array}{l}46 \\
46 \\
\end{array}$ & $\begin{array}{l}18 \\
30\end{array}$ & 5.38 \\
\hline Deltamethrin & 506.9 & $\begin{array}{c}506.2>281.0 \\
506.2>92.9\end{array}$ & $\begin{array}{l}38 \\
38 \\
\end{array}$ & $\begin{array}{l}14 \\
62 \\
\end{array}$ & 1.87 \\
\hline Permethrin & 183.0 & $\begin{array}{l}183.0>109.0 \\
183.0>155.0\end{array}$ & $\begin{array}{l}40 \\
40\end{array}$ & $\begin{array}{c}18 \\
8\end{array}$ & 1.14 \\
\hline Bifenthrin & 440.4 & $\begin{array}{l}440.4>181.1 \\
440.4>165.9\end{array}$ & $\begin{array}{l}18 \\
18\end{array}$ & $\begin{array}{l}16 \\
54\end{array}$ & 2.15 \\
\hline Amitraz & 294.0 & $\begin{array}{l}294.0>181.1 \\
294.0>211.0\end{array}$ & $\begin{array}{l}28 \\
28\end{array}$ & $\begin{array}{l}24 \\
12\end{array}$ & 2.06 \\
\hline Coumaphos & 363.2 & $\begin{array}{l}363.2>227.0 \\
363.2>307.1\end{array}$ & $\begin{array}{l}46 \\
46 \\
\end{array}$ & $\begin{array}{l}26 \\
18\end{array}$ & 7.42 \\
\hline $\begin{array}{c}\text { Bromopropylat } \\
\text { e }\end{array}$ & 341.4 & $\begin{array}{l}341.4>57.0 \\
341.4>71.0\end{array}$ & $\begin{array}{l}40 \\
40\end{array}$ & $\begin{array}{l}24 \\
30\end{array}$ & 7.52 \\
\hline Dichlorvos & 221.0 & $\begin{array}{c}221.0>79.0 \\
221.0>109.0\end{array}$ & $\begin{array}{l}36 \\
36\end{array}$ & $\begin{array}{l}32 \\
18\end{array}$ & 4.96 \\
\hline Diazinone & 305.2 & $\begin{array}{l}305.2>153.1 \\
305.2>169.1 \\
\end{array}$ & $\begin{array}{l}44 \\
44 \\
\end{array}$ & $\begin{array}{l}20 \\
22 \\
\end{array}$ & 7.89 \\
\hline Malathion & 331.2 & $\begin{array}{c}331.2>99.0 \\
331.2>127.0\end{array}$ & $\begin{array}{l}28 \\
28\end{array}$ & $\begin{array}{l}24 \\
12 \\
\end{array}$ & 9.07 \\
\hline Parathion & 292.1 & $\begin{array}{l}292.1>181.0 \\
292.1>221.0\end{array}$ & $\begin{array}{l}26 \\
26\end{array}$ & $\begin{array}{l}12 \\
10\end{array}$ & 2.05 \\
\hline Dimethoate & 230.0 & $\begin{array}{l}230.0>125.0 \\
230.0>199.0\end{array}$ & $\begin{array}{l}24 \\
24\end{array}$ & $\begin{array}{l}22 \\
10\end{array}$ & 3.05 \\
\hline Omethoate & 214.0 & $\begin{array}{l}214.0>155.0 \\
214.0>183.0\end{array}$ & $\begin{array}{l}26 \\
26\end{array}$ & $\begin{array}{l}16 \\
12\end{array}$ & 1.08 \\
\hline Thiametoxam & 292.2 & $\begin{array}{l}292.2>181.1 \\
292.2>211.0\end{array}$ & $\begin{array}{l}26 \\
26 \\
\end{array}$ & $\begin{array}{l}24 \\
12 \\
\end{array}$ & 2.08 \\
\hline Methomyl & 163.1 & $\begin{array}{l}163.1>104.6 \\
163.1>122.6 \\
\end{array}$ & $\begin{array}{l}36 \\
36 \\
\end{array}$ & $\begin{array}{l}24 \\
16 \\
\end{array}$ & 3.78 \\
\hline
\end{tabular}

${ }^{\mathrm{a}} \mathrm{CV}$ - cone voltage

${ }^{\mathrm{b}} \mathrm{CE}$ - collision energy

${ }^{\mathrm{c}} \mathrm{RT}$ - retention time

\section{Method validation}

To ensure that the optimized procedure was suitable for the application in routine analysis, the analytical performance parameters were determined and assessed. The obtained linearity (R2) in the range $5-250 \mathrm{ng} / \mathrm{mL}$ for all compounds was better than 0.99 . The determined LODs and LOQ were lower than the reporting level $10 \mu \mathrm{g} / \mathrm{kg}$, except in the case of coumaphos and thiametoxam where obtained LOQ was 11.4 and $12.2 \mu \mathrm{g} / \mathrm{kg}$, respectively (Table 
2). Furthermore, the obtained LOQ values were substantially lower than the established MRLs for pesticides in honey (EU Pesticide database; EC, 2010).

The recovery experiments exhibited values within the required range 70$120 \%$, laid down as acceptable in the SANCO document (2013), except for omethoate, whereas the obtained recovery was 152.7 and $181.2 \%$ for 10 and 50 $\mu \mathrm{g} / \mathrm{kg}$, respectively. According to some previous investigations (Tomasini et al. 2012), a recovery value over $150 \%$ is considered as high matrix effect. Such effect occurs when molecules co-eluting with the compounds of interest alter the ionization efficiency in reference to conditions in absence of matrix. Practically, it means that for accurate omethoate quantification we shall use matrix-matched calibration curve that will compensate the matrix effect. Optimized method exhibited satisfactory precision; the obtained RSD, for all compounds investigated, for both validation levels, was lower than $20 \%$ (Table 2).

Table 2. Validation parameters for the pesticide compounds according to the SANCO requirements [9]

\begin{tabular}{|c|c|c|c|c|}
\hline Pesticide & $\mathrm{LOD} / \mu \mathrm{g} / \mathrm{kg}$ & $\mathrm{LOQ} / \mu \mathrm{g} / \mathrm{kg}$ & $\begin{array}{c}\text { Recovery at } 10 \\
\mu \mathrm{g} / \mathrm{kg}(\mathrm{RSD} / \%)\end{array}$ & $\begin{array}{c}\text { Recovery at 50 } \\
\mu \mathrm{g} / \mathrm{kg}(\mathrm{RSD} / \%)\end{array}$ \\
\hline Carbaryl & 1.8 & 5.8 & $80.3(8.5)$ & $81.7(8.4)$ \\
\hline Carbofuran & 2.5 & 8.1 & $79.7(12.6)$ & $89.4(6.2)$ \\
\hline Fenvalerate & 1.4 & 4.7 & $91.1(9.4)$ & $84.6(16.2)$ \\
\hline Cypermethrin & 1.9 & 6.2 & $81.3(13.5)$ & $91.8(13.0)$ \\
\hline Deltamethrin & 0.5 & 1.7 & $86.9(9.8)$ & $77.6(7.4)$ \\
\hline Permethrin & 1.6 & 5.2 & $87.0(10.6)$ & $85.0(14.8)$ \\
\hline Bifenthrin & 2.3 & 7.6 & $76.9(17.0)$ & $75.0(19.3)$ \\
\hline Amitraz & 1.8 & 6.0 & $91.7(10.1)$ & $80.7(11.3)$ \\
\hline Coumaphos & 3.4 & 11.4 & $93.7(13.2)$ & $83.2(7.3)$ \\
\hline Bromopropylate & 2.8 & 9.2 & $96.3(12.4)$ & $92.7(7.6)$ \\
\hline Dichlorvos & 0.5 & 1.6 & $73.8(9.5)$ & $74.4(6.9)$ \\
\hline Diazinone & 1.2 & 4.0 & $92.1(13.7)$ & $82.2(5.8)$ \\
\hline Malathion & 0.9 & 3.9 & $97.1(12.9)$ & $104.1(12.1)$ \\
\hline Parathion & 1.3 & 3.3 & $82.5(8.8)$ & $79.6(5.7)$ \\
\hline Dimethoate & 2.4 & 7.8 & $84.1(14.5)$ & $81.0(7.7)$ \\
\hline Omethoate & 3.0 & 9.7 & $152.7(11.3)$ & $181.2(9.6)$ \\
\hline Thiametoxam & 3.7 & 12.2 & $100.2(15.9)$ & $102.4(9.7)$ \\
\hline Methomyl & 2.0 & 6.6 & $75.7(8.6)$ & $83.4(7.7)$ \\
\hline
\end{tabular}

The recovery experiments revealed values within the required range 70$120 \%$, laid down in the SANCO document (2013), except for omethoate, whereas the obtained recovery was 152.7 and $181.2 \%$ for 10 and $50 \mu \mathrm{g} / \mathrm{kg}$, respectively. According to some previous investigations (Tomasini et al. 2012), a recovery value of over $150 \%$ is considered as high matrix effect. Such effect occurs when molecules co-eluting with the compounds of interest alter the ionization efficiency in reference to conditions in absence of matrix. Practically, it means that for accurate omethoate quantification we shall use matrix-matched calibration curve that will compensate the matrix effect. 


\section{Honey samples analysis}

When analyzing real honey samples, internal quality control was implemented to provide the correct working of the method and the UHPLCMS/MS system. A duplicate analysis of honey samples was accompanied with a recovery experiment within each batch, to check the extraction efficiency. Positive samples were quantified with reference to the four - level calibration curves obtained for each batch of samples. Furthermore, it enables avoiding adverse effects impact on the quantification process coming from the instrument. Each positive result (over the analyte reporting level) was corrected for the recovery rate obtained for each batch of samples.

The method was applied to 50 multifloral honey samples collected at individual beekeepers from different geographical locations in Macedonia. In these samples five different pesticides, namely bromopropylate, methomyl, diazinone, fenvalerate, dichlorvos, cypermethrin and omethoate were detected in concentration range between 6.9 and $26.5 \mu \mathrm{g} / \mathrm{kg}$ in 16 honey samples $(32 \%)$ (Table 3). The positive findings were confirmed by acquiring two transitions for quantification and identification in compliance with the EU guidelines (SANCO, 2013). The findings demonstrated that the method could be useful for analyzing pesticides in real samples of honey. Carbaryl, carbofuran, fenvalerate, deltamethrin, permethrin, bifenthrin, amitraz, coumaphos, malathion, parathion, dimethoate and thiametoxam were present in concentrations lower than the LOQ (Table 3).

Table 3. Positive findings of pesticides in 50 honey samples, using the proposed method.

\begin{tabular}{|c|c|c|c|c|}
\hline Pesticide & $\begin{array}{c}\text { Min } \\
(\mu \mathrm{g} / \mathrm{kg})\end{array}$ & $\begin{array}{c}\text { Max } \\
(\mu \mathrm{g} / \mathrm{kg})\end{array}$ & $\begin{array}{c}\text { Mean }^{\mathrm{a}} \\
(\mu \mathrm{g} / \mathrm{kg})\end{array}$ & $\begin{array}{c}\text { MRL } \\
(\mu \mathrm{g} / \mathrm{kg})\end{array}$ \\
\hline Cypermethrin & $<6.2$ & 24.6 & $16.5(2)^{\mathrm{b}}$ & 50 \\
\hline Bromopropylate & $<9.2$ & 21.5 & $15.8(3)^{\mathrm{b}}$ & 10 \\
\hline Dichlorvos & $<1.6$ & 11.5 & $9.2(2)^{\mathrm{b}}$ & 10 \\
\hline Diazinone & $<4.0$ & 26.5 & $24.0(3)^{\mathrm{b}}$ & 10 \\
\hline Fenvalerate & $<7.8$ & 10.6 & $--(1)^{\mathrm{b}}$ & 10 \\
\hline Omethoate & $<9.7$ & 16.3 & $14.0(2)^{\mathrm{b}}$ & 10 \\
\hline Methomyl & $<6.6$ & 24.1 & $18.5(3)^{\mathrm{b}}$ & 10 \\
\hline
\end{tabular}

${ }^{a}$ mean value of positive findings

${ }^{\mathrm{b}}$ number of positive findings

Bromopropylate, diazinone and methomyl were detected and confirmed over the limits of quantification at three samples ( $6 \%$ positivity), cypermethrin, dichlorvos and omethoate at two samples ( $4 \%$ positivity) and fenvalerate at one honey sample ( $2 \%$ positivity). The determined concentrations for all positive findings for bromopropylate, diazinone, omethoate and methomyl (Table 3), exceeded the required reporting concentration level according to EU pesticide database, being $10 \mu \mathrm{g} / \mathrm{kg}$. For dichlovos the respective level $(10 \mu \mathrm{g} / \mathrm{kg})$ was exceeded only at one sample, while for cypermethrin, the detected concentration levels for both positive samples were below the level of interest $(50 \mu \mathrm{g} / \mathrm{kg})$. 
The presence of methomyl, fenvalerate and omethoate in the analyzed honey samples can be attributed to environment contamination since there are no known beekeeping practices using these pesticides (Bogdanov, 2006). On the other hand, bromopropylate and diazinone are known as used against parasites and diseases in the conventional beekeeping practice (Bogdanov, 2006; Fernandez-Garsia et al. 1994).

Likewise, other researchers reported no significant residues of insecticides in honey (Bogdanov, 2006; Naccari et al. 2014). Several investigations conducted on different types of honey and applying various analytical methods showed, instead, the presence of pesticides in significant extent (RodríguezLópez et al. 2014; Herrera et al. 2005; Mukherjee, 2009). In another study of honey with origin from Spain and Portugal (Blasco et al. 2003) most of the compounds found were chlorinated pesticides.

According to some previous publications (Bogdanov, 2006) the relatively low concentration of pesticides in honey seems to be due to a filtering effect of bees. Initially high pesticides concentrations in nectars are decreased approximately by factor of 1000. In addition, many of the modern pesticides used today are unstable and disintegrate quickly after use. Considering the fact that pesticide residues concentrations found in honey are comparable to the ones found in other foodstuffs (Kuchen et al. 1998) and the low honey inclusion in the diet, is can be concluded that pesticide residues found in honey within this study, are safe from toxicological point of view.

\section{CONCLUSION}

The QuEChERS in combination with UHPL-MS/MS method provides high-quality results, minimizes the number of analytical steps, and uses reagents in small quantities. The method showed good performance, which was verified through the method validation procedure. The achieved recoveries and precision were acceptable, and in line with the legislation requirements. Matrix-matched calibration curves should be used for accurate quantification of the positive findings. The data for pesticide findings from this study and the frequency of pesticide detection are an indication for the presence of both direct and indirect honey contamination. However, no significant amounts of investigated pesticides are detected, that could pose health risk to the consumers. This research is the first insight on the monitoring of residues of pesticides in honey samples from different geographical parts of Macedonia.

\section{ACKNOWLEDGEMENTS}

The authors are grateful to the Faculty for veterinary medicine from Skopje, Ss Cyril and Methodius University, for the financial support of the study. 


\section{REFERENCES}

Amendola, G., Pelosi, P., Dommarco, R. (2011). Solid-phase extraction for multi-residue analysis of pesticides in honey, J. Environ. Sci. Health., Part B, 46, 24-34.

Anastassiades, M.; Lehotay, S. J.; Stajnbaher, D.; Schenck, F. J. (2003). Fast and easy multiresidue method employing acetonitrile extraction/partitioning and "dispersive solid-phase extraction" for the determination of pesticide residues in produce $\mathrm{J}$. AOAC Int., 86, 412-431.

Blasco, C., Fernández, M., Pena, A., Lino, C., Silveira, M.I., Font, G., Picó, Y. (2003). Assessment of Pesticide Residues in Honey Samples from Portugal and Spain, J. Agric. Food Chem., 51 (27), 8132-8138.

Bogdanov, S. (2006). Contaminants in bee products, Apidologie, 37, 1-18.

Commission Regulation (EU) 37/2010 of 22 December 2009 on pharmacologically active substances and their classification regarding maximum residue limits in foodstuffs of animal origin, OJ L 15/1, 20.01.2010, p. 1-2 (ANNEX I).

Eisaa, A.A., Hassan, A.S.M., Abd El Rahman, T.A. (2014). Determination of total Aflatoxins and Carbamate Pesticide Residues in Some Bee Honey Samples, Using QuEChERS method and High Performance Liquid Chromatography, Food and Public Health, 4(5):209-2013.

EU Pesticides Database. http://ec.europa.eu/sanco_ pesticides/public/?event=commodity. selection, accessed on February 9th 2015.

EU, 2001. Council Directive 2001/110 relating to honey. Official Journal of the European Communities.

Fernandez-Garsia, M.A., Riol-Melgar, M.J., Herrero-Latorre, C., Fernandez-Garsia, M.I. (1994). Evidence for the safety of coumaphos, diazinon and malathion residues in honey, Vet. Hum. Toxicol., 36(5), 429-432.

Fidente, P., Seccia, S., Vanni, F., Morrica, P. (2005). Analysis of nicotinoid insecticides residues in honey by solid matrix partition clean-up and liquid chromatographyelectrospray mass spectrometry, J. Chromatogr. A, 1094, 175-178.

Herrera, A., Perez-Arquillue, C., Conchello, P., Bayarri, S., Lazaro, R., Yahu, C., Arini, A. (2005). Determination of pesticides and PCBs in honey by solid-phase extraction clean-up followed by gas chromatography with electron-capture and nitrogen-phosphorus detection. Anal. Bioanal. Chem. 381, 695-701.

Kuchen, A., Muller, F., Farine, M., Zimmermann, H., Blaser, O., Wuthrich, O. (1998). Die mittlere tagliche Aufname von Pestiziden und anderen Fremdstoffen uber die Nahrung in der Schweiz, Mitt. Geb. Lebensm. Hyg., 90, 78-107.

Mukherjee, I. (2009). Determination of Pesticide residues in Honey Samples, Bull. Environ. Contam. Toxicol. 83, 818-821.

Naccari, C., Macaluso, A., Giangrosso, G., Naccari, F., Ferrantelli, V. (2014). Risk Assessment of Heavy Metals and Pesticides in Honey From Sicily (Italy), Journal of Food Research, 3(2) 107-117.

Orso, D., Martins, M.L., Donato, F.F., Rizzetti, T.M., Kemmerich, M., Adaime, M.B., Zanella, R. (2014). Multiresidue Determination of Pesticide Residues in Honey by Modified QuEChERS Method and Gas Chromatography with Electron Capture Detection, J. Braz. Chem. Soc., 25 (8), 1355-1364. 
Rodríguez López, D., Ahumada, D.A., Díaz, A.C., Guerrero, J.A. (2014). Evaluation of pesticide residues in honey from different geographic regions of Colombia, Food Control, 37, 33-40.

Sampaio, M.R.F., Tomasini, D., Cardoso, L.V., Caldas, S.S., Primel, E.G. (2012). Determination of Pesticide Residues in Sugarcane Honey by QuEChERS and Liquid Chromatography, J. Braz. Chem. Soc., 23(2), 197-205.

SANCO, Commission of the European Communities, Guidance document on analytical quality control and validation procedures for pesticide residues analysis in food and feed, Document No. SANCO/12571/2013, Uppsala Sweden, 19/11/2013.

Tanner. G., Czerwenka, C. (2011). LC-MS/MS analysis of neonicotinoid insecticides in honey: methodology and residue findings in Austrian honeys, J. Agric. Food. Chem., 59(23), 12271-12277.

Tomasini, D., Sampaio, M.R.F., Caldas, S.S., Buffon, J.G., Duarte F.A., Primel, E.G. (2012). Simultaneous determination of pesticides and 5-hydroxymethylfurfural in honey by modified QuEChERS method and liquid chromatography coupled to tandem mass spectrometry, Talanta, 99, 380-386.

Wallner, K. (1999). Varroacides and their residues in bee products, Apidologie, 30, 235248. 